decreto supremo. Quiero finalizar, suscribiendo formalmente a nombre de los Colegios Profesionales nuestro compromiso de avanzar en el correcto ejer- cicio de nuestras profesiones.

Dr. Pablo Rodríguez.

Santiago, 10 de Junio de 2009.

\title{
Crónica
}

\section{INVITACIÓN AL XXXII CONGRESO CHILENO DE OBSTETRICIA Y GINECOLOGÍA: UN TRABAJO EN EQUIPO}

Hoy la medicina y particularmente nuestra especialidad, está sujeta a diversos cambios que nos ponen como principal desafío fortalecer los trabajos en equipo. Vemos cada día como el contacto electrónico reemplaza al contacto directo en múltiples áreas, incluyendo especialmente la difusión del conocimiento. No obstante, creemos que la difusión presencial y la interacción directa con los docentes, mantiene un rol trascendente para el saber de nuestra especialidad. Es por esto que la realización del Congreso Chileno de Obstetricia y Ginecología posee una especial relevancia, como un foro periódico de nuestra especialidad, para la puesta al día de conocimientos, así como la posibilidad de presentar nuestras experiencias clínicas a través de Contribuciones.

Bajo ese escenario, el actual Directorio de la Sociedad Chilena de Obstetricia y Ginecología, tiene dentro de sus metas incorporar a través de acciones concretas a las Sociedades Relacionadas, así como también a instituciones nacionales e internacionales ligadas a la especialidad.

Dentro de este propósito, en nuestro próximo XXXII Congreso Chileno de Obstetricia y Ginecología, a realizarse los días 22, 23 y 24 de noviembre en Viña del Mar, hemos hecho un esfuerzo conjunto entre el Centro de Diagnóstico e Investigaciones Perinatales y Ginecológicas de la Universidad Ca- tólica (CEDIP UC) y la Sociedad Chilena de Fertilidad, organizar en forma conjunta nuestra actividad científica bianual.

A este trabajo en equipo, también se sumaron la Sociedad Chilena de Climaterio (SOCHICLIM), la Sociedad Chilena de Ginecología Infantil y de la Adolescencia (SOGIA), The International Society for the Developmental Origins of Health and Disease (DOHaD) y el American College of Obstetricians and Gynecologists (ACOG), quienes estarán presentes a través de módulos y cursos.

La unión de todas estas entidades, nos permitirán contar con los más altos expositores nacionales e internacionales en los diversos campos de la ginecología y obstetricia. Será una excelente oportunidad para fortalecer nuestros conocimientos, mediante esta actividad de capacitación continúa y el éxito, una prueba clara de nuestra capacidad de organización.

Invitamos a médicos socios(as) y no socios(as) que ejercen la especialidad a lo largo de todo Chile, a participar activamente en esta reunión, que sin lugar a dudas contribuirá a perfeccionar nuestros conocimientos y capacitarnos para una mejor atención en la salud integral de la mujer.

Un muy cordial saludo,

Dr. Eugenio Suárez Pacheco. Presidente SOCHOG. 